\title{
Assessment of the Genetic Diversity of Ulex europaeus in Maui, California, Hawaii and New Zealand by a Method of Microsatellite Markers ${ }^{\dagger}$
}

\author{
Mika Hozawa * and Eiji Nawata \\ Kyoto University; nawata.eiji.7c@kyoto-u.jp \\ * Correspondence: hozawa.mika.x12@kyoto-u.jp; Tel.: +81-90-9606-4385 \\ + Presented at the 1st International Electronic Conference on Plant Science, 1-15 December 2020; Available \\ online: https://iecps2020.sciforum.net/.
}

Published: 30 November 2020

\begin{abstract}
One of the serious invasive, allohexaploid plant species, Ulex europaeus is originally from Western Europe and spreading to the world by some unknown pathways. Plants often show phenotypic plasticity according to the environments, but making it clear that the differences are derived from environmental or genetic effects is very important for further study. Thus, the aim of this study was to assess the genetic distances of Ulex europaeus from four different regions such as Maui, California, Hawaii and New Zealand. Microsatellite method which has been used frequently to test the genetic distances of the hexaploid plant species recently was used for the assessment because normal single nucleotide polymorphism (SNP) often shows genotypic ambiguity on hexaploids. We tested the leaf samples of 37 mother trees from four regions (Maui: 11, California: 4, Hawaii: 7, New Zealand: 15) at five microsatellite loci. After polymerase chain reaction analyses (PCR), dinucleotide-repeat motifs (DRMs) were counted and compared to test the genetic distances of the samples. As a result, dendrogram and analysis of molecular variance (AMOVA) showed that Ulex europaeus sampled in four different regions were genetically very close. If they show any morphological differences, they are inferred to be derived from environmental effects.
\end{abstract}

Keywords: allohexaploid 2; genentic distances 3; invasive species 4; microsatellite 5; phenotypic plasticity

\section{Introduction}

Phenotypic plasticity is an important trait for the adaptation of introduced $U$. europaeus in many places in the world. In order to explain the mechanism of the adaptation of $U$. europaeus, genetic assessment of the samples collected in unique sites, such as Maui, California, Hawaii and New Zealand, should have been completed prior to the other assessments. This helped avoid ambiguous discussion about the results, such that the morphological and physiological differences could be derived from the differences in genetic traits. Microsatellite research on human and animal genomes is commonly reported, whereas similar research on plants has not yet been reported very often [1]. $U$. europaeus is a hexaploid species evolved from the hybridization of a diploid and tetraploid of different Ulex lineages [2,3]. As mentioned by multiple authors in previous studies, assessing the genetic differences of the plants of allohexaploid by methods using normal SNP (single nucleotide polymorphism) is not possible [4]. However, the genetic differences of many allohexaploid species also need to be identified in population genetics. For this reason, analytical methods using microsatellites have been used and progress is being made towards efficient genetic markers in population genetics [5]. SSR (Simple Sequence Repeats) method, one of the representative methods using microsatellites, has been used for genotyping plants for over 20 years because it is highly informative and can be experimentally compared [5]. One of the reasons why SSRs is used widely for the population genetics is that it enables the creation of sequence-based linkage maps that show the difference visually. 


\section{Experiments}

\subsection{Materials and Methods}

Samples were taken in Maui, Hawaii, California and New Zealand from July 2016 to November 2017 (Table 1). Tissue samples of the leaves were taken on FTA ${ }^{\circledR}$ Plant Card (Whatman ${ }^{\circledR}$ Co., Ltd.) and prepared for the further analysis according to the protocol by Whatman ${ }^{\circledR}$ for PCR.

Table 1. Location and coordinates of Ulex europaeus sampled for PCR experiments.

\begin{tabular}{|c|c|c|c|c|c|}
\hline Location & Mother Tree & Latitude & Longitude & Altitude (m) & Habitat \\
\hline \multirow[t]{11}{*}{ Maui } & \#22 & N20.76 & W156.27 & 1758 & Ranch \\
\hline & \#23 & N20.76 & W156.27 & 1823 & Ranch \\
\hline & $\# 26$ & N20.77 & W156.26 & 1767 & Ranch \\
\hline & $\# 27$ & N20.77 & W156.26 & 1763 & Ranch \\
\hline & \#28 & N20.77 & W156.26 & 1763 & Ranch \\
\hline & \#29 & N20.78 & W156.25 & 1773 & Ranch \\
\hline & $\# 30$ & N20.78 & W156.25 & 1768 & Ranch \\
\hline & $\# 33$ & N20.79 & W156.25 & 1656 & Ranch \\
\hline & $\# 35$ & N20.8 & W156.28 & 1060 & Forest \\
\hline & \#36 & N20.8 & W156.28 & 1067 & Forest \\
\hline & \#37 & N20.8 & W156.28 & 1046 & Forest \\
\hline California & $\# 40,41,42,43$ & N37.15 & W122.34 & $33,33,34,31$ & Fallow land \\
\hline \multirow[t]{7}{*}{ Hawaii } & $\# 49$ & N19.72 & W155.44 & 2004 & Ranch \\
\hline & $\# 50$ & N19.72 & W155.43 & 2058 & Ranch \\
\hline & \#51 & N19.93 & W155.41 & 2015 & Ranch \\
\hline & $\# 52$ & N19.73 & W155.39 & 1952 & Ranch \\
\hline & $\# 52-2$ & N19.73 & W155.39 & 1952 & Ranch \\
\hline & $\# 53$ & N19.74 & W155.37 & 1929 & Ranch \\
\hline & \#55 & N19.77 & W155.36 & 1980 & Ranch \\
\hline \multirow[t]{5}{*}{ New Zealand } & $\mathrm{N} 2-1,2,3$ & S36.88 & E174.84 & 0 & Fallow land \\
\hline & N5-1, 2, 3 & S37.86 & E175.82 & 97 & Roadside of a ranch \\
\hline & $\mathrm{N} 8-1,2,3$ & S38.99 & E175.76 & 538 & Fallow land with grass \\
\hline & $S 1-1,2,3$ & S43.8 & E173 & 623 & Ranch \\
\hline & $S 4-1,2,3$ & S43.5 & E172.52 & 38 & Roadside of a ranch \\
\hline
\end{tabular}

Five primers (Table 2) were prepared for PCR (Polymerase chain reaction) used in the previous research by Hornoy et al. [6]. They chose eight microsatellites loci from Genetic Identification Services (GIS Inc., Chatsworth, CA, USA) and got clear results from 6 loci. We used five of them.

The enzyme, KOD FX Neo of TOYOBO Co., Ltd. was used for PCR experiments. PCR reactions were performed for each locus in $25 \mu \mathrm{L}$ containing $12.5 \mu \mathrm{L}$ of buffer, $2.5 \mu \mathrm{L}$ of dNTP, $9 \mu \mathrm{L}$ of deionized and sterilized water, $0.4 \mu \mathrm{L}$ each of Primers (F and R), and $0.2 \mu \mathrm{L}$ of enzyme.

PCR was done by an initial denaturation step at $94^{\circ} \mathrm{C}$ for $2 \mathrm{~min}, 35$ cycles with $10 \mathrm{~s}$ denaturation at $98^{\circ} \mathrm{C}, 30 \mathrm{~s}$ hybridization of primers at $60^{\circ} \mathrm{C}$ and $1 \mathrm{~min}$ elongation at $68^{\circ} \mathrm{C}$, with a final elongation step at $68{ }^{\circ} \mathrm{C}$ for $7 \mathrm{~min}$, using iCycler (Bio Rad Laboratories, California, USA). After checking the condition of the bands at electrophoresis with $2 \%$ of agarose gel, next generation sequencing of the PCR products was conducted by Takara Bio Inc. (Kusatsu, Shiga, Japan). 
Table 2. Five microsatellite loci used in the experiments.

\begin{tabular}{ccc}
\hline Locus & Primers & [Primers] $(\mu \mathrm{M})$ \\
\hline A110 & F: 5'-CTATGGTGAATTTGTGATACAC-3' & 0.35 \\
& R: 5'-ACCTTGTTGCATCTTTACC-3' \\
A125 & F: 5'-GCATATACATACCCGAGGTAAG-3' & 0.26 \\
\multicolumn{3}{c}{ R: 5'-AACCTGATGAAATGCACTATTC-3' } \\
B4 & F: 5'-GGGCTCTGGCTCTGATAC-3' & 0.2 \\
& \multicolumn{2}{c}{ R: 5'-TTGGATTAACCAACTTTCCTC-3' } \\
B104 & F: 5'-GAACCTTATTCACTGGAATCTG-3' 0.3 \\
& \multicolumn{2}{c}{ R: 5'-CCCTTTTCTTTCCTTTCTTAAC-3' } \\
B123 & F: 5'-AATTTGCCTGACATTGTTACTC-3' 0.22 \\
& \multicolumn{2}{c}{ R: 5'-AGACCGTGTTCATTATGGTTAG-3' }
\end{tabular}

\subsection{Data Analysis}

Genetic diversity among and within populations was estimated by the analysis of molecular variance with the software GenAlEx [7]. In addition, a cluster dendrogram was calculated and indicated by software R ver. 3.3.2 [8].

\subsection{Estimation of Genetic Distance}

All the FASTA data were checked with software ApE (Utah University, free software) and effective length of the PCR product was determined manually. Only dinucleotide-repeat motifs (DRMs) were focused this time because they have been identified as an enhancer that expresses gene [9]. Furthermore, as the length of DNA fragment is often changed affected by insertion or deletion, counting the repeat numbers directly was suggested to determine the genotypes of SSR (Short Sequence Repeat) or STR (Short Tandem Repeat) marker more correctly [10]. In this reason, the repeat number of the most common motifs found in five loci, GT/TG, CT/TC, AG/GA, AG/GA, AG/GA respectively were counted by each locus using a software SEAVIEW [11] and amended accordingly to the mean effective product size (160 bp this time) for the comparison. By using the data taken, AMOVA was tested to see the genetic variation and cluster analysis for making dendrogram with 1000 bootstraps was done by using R. ver. 3.3.2 [8].

\section{Results and Discussions}

\subsection{Cluster Analysys}

The number of each target dinucleotide repeats were counted using SEAVIEW [11] as shown in Table 3.

Table 3. Dinucleotide repeats number of 36 individuals. M: Maui, C: California, H: Hawaii, N-N: New Zealand North Island, N-S: New Zealand South Island.

\begin{tabular}{ccccccc}
\hline & & \multicolumn{5}{c}{ Selected Loci } \\
\hline Sample NO & Population & A110 & A125 & B4 & B104 & B123 \\
\hline 22 & M & 12 & 16 & 0 & 0 & 10 \\
23 & M & 0 & 0 & 0 & 0 & 23 \\
26 & M & 10 & 0 & 0 & 8 & 15 \\
27 & M & 12 & 0 & 0 & 0 & 0 \\
28 & M & 0 & 0 & 0 & 2 & 0 \\
29 & M & 17 & 0 & 0 & 6 & 13 \\
30 & M & 0 & 0 & 0 & 0 & 5 \\
33 & M & 5 & 0 & 0 & 8 & 26 \\
35 & M & 12 & 0 & 27 & 0 & 21 \\
36 & M & 11 & 0 & 0 & 13 & 0
\end{tabular}




\begin{tabular}{|c|c|c|c|c|c|c|}
\hline 37 & $\mathrm{M}$ & 14 & 0 & 12 & 0 & 19 \\
\hline 40 & C & 12 & 15 & 0 & 14 & 0 \\
\hline 41 & C & 0 & 0 & 0 & 0 & 19 \\
\hline 42 & C & 9 & 0 & 23 & 0 & 18 \\
\hline 43 & C & 11 & 27 & 0 & 14 & 15 \\
\hline 49 & $\mathrm{H}$ & 5 & 0 & 36 & 0 & 20 \\
\hline 50 & $\mathrm{H}$ & 14 & 0 & 36 & 0 & 0 \\
\hline 51 & $\mathrm{H}$ & 17 & 0 & 0 & 2 & 16 \\
\hline 52 & $\mathrm{H}$ & 13 & 0 & 0 & 0 & 19 \\
\hline $52-2$ & $\mathrm{H}$ & 0 & 0 & 0 & 0 & 39 \\
\hline 53 & $\mathrm{H}$ & 13 & 48 & 0 & 38 & 15 \\
\hline 55 & $\mathrm{H}$ & 0 & 0 & 0 & 0 & 17 \\
\hline N2-1 & $\mathrm{N}-\mathrm{N}$ & 4 & 7 & 11 & 4 & 17 \\
\hline N2-2 & N-N & 0 & 0 & 0 & 4 & 18 \\
\hline N2-3 & $\mathrm{N}-\mathrm{N}$ & 0 & 2 & 5 & 6 & 14 \\
\hline N5-1 & $\mathrm{N}-\mathrm{N}$ & 0 & 22 & 0 & 3 & 0 \\
\hline N5-2 & N-N & 0 & 22 & 3 & 7 & 0 \\
\hline N5-3 & $\mathrm{N}-\mathrm{N}$ & 0 & 22 & 0 & 10 & 14 \\
\hline N8-1 & $\mathrm{N}-\mathrm{N}$ & 3 & 23 & 0 & 0 & 0 \\
\hline N8-2 & $\mathrm{N}-\mathrm{N}$ & 15 & 26 & 43 & 3 & 13 \\
\hline N8-3 & $\mathrm{N}-\mathrm{N}$ & 11 & 21 & 41 & 0 & 0 \\
\hline S1-1 & N-S & 12 & 20 & 4 & 6 & 16 \\
\hline S1-2 & N-S & 18 & 26 & 7 & 15 & 0 \\
\hline S1-3 & N-S & 13 & 0 & 32 & 20 & 0 \\
\hline S4-1 & N-S & 0 & 24 & 37 & 5 & 10 \\
\hline S4-2 & N-S & 12 & 26 & 0 & 0 & 24 \\
\hline S4-3 & N-S & 21 & 11 & 0 & 0 & 0 \\
\hline
\end{tabular}

As the next step, the data of Table 3 was analyzed by software R ver. 3.3.2 [8] for the dendrogram of Figure 1 (1000 boot strap) in order to visualize the correlation data of microsatellite results. The vertical axis is labelled distance and refers to a distance measure between compounds or compound clusters. The height of the node can be thought of as the distance value between the right and left sub-ranch clusters. When $\mathrm{D}$ (distance) and $\mathrm{C}$ (correlation) between compound cluster, $\mathrm{D}=1-\mathrm{C}$. If compounds are highly correlated, they will have a correlation value close to 1 , and the $\mathrm{D}(1-\mathrm{C})$ will have a value close to zero. Therefore, highly correlated clusters are nearer the bottom of the dendrogram. As clusters increase in size, their abundance profiles become more general. From the result of the dendrogram (Figure 1), U. europaeus sampled in Maui, California, Hawaii and New Zealand show the similarity in genetic distances. 


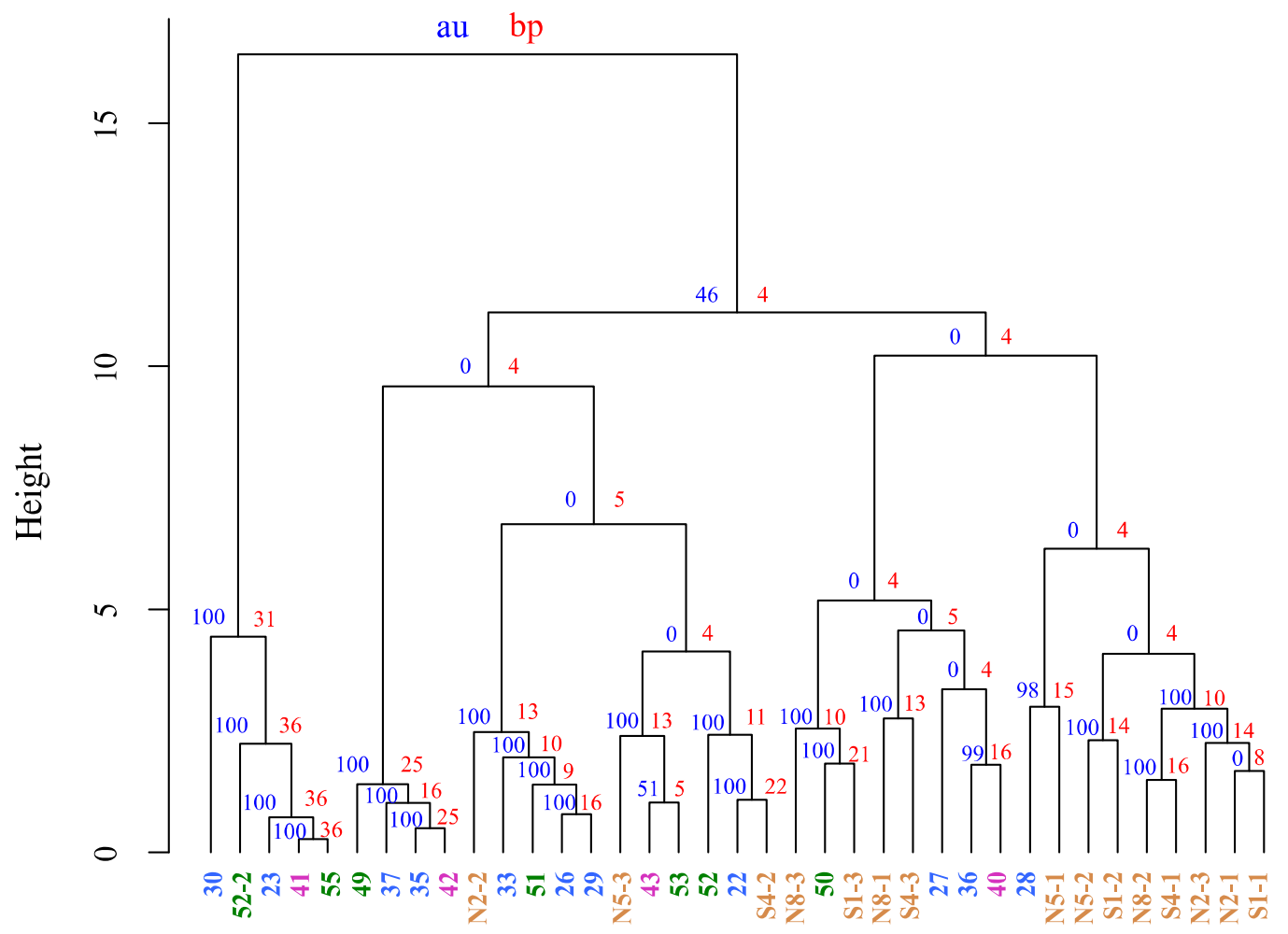

Figure 1. Dendrogram of Ulex europaeus sampled in Maui, California, Hawaii and New Zealand after 1000-boot strap. Blue: Maui, green: Hawaii, pink: California, yellow with N: New Zealand North Island, yellow with S: New Zealand Soutn Island. Au, bp are two types of $p$-values (\%): au (approximately unbiased) $p$-value and bp (bootstrap probability) value.

\subsection{Analysis of Molecular Variance}

In addition, the data of Table 3 was analyzed by GenAlEx to see the genetic variation. Table 4 shows the result of AMOVA.

Table 4. Results of the molecular variance of $U$. europaeus sampled in 3 regions for this study. Probability, P (rand $\geq$ data), for PhiPT is based on standard permutation across the full data set.

\begin{tabular}{cccccc}
\hline Source & df & SS & MS & Est. Var. & \% \\
\hline Among Pops & 4 & 2960.2 & 740.05 & 27.79 & $5 \%$ \\
Within Pops & 32 & $17,276.99$ & 539.91 & 539.91 & $95 \%$ \\
Total & 36 & $20,237.19$ & & 567.69 & $100 \%$ \\
Stat & Value & P (rand $\geq$ data) & & \\
PhiPT & 0.05 & 0.11 & & & \\
\hline
\end{tabular}

Though the $p$-value was not significant, the results inferred that the most variation (95\%) was detected among populations, and just $5 \%$ attributed to variation within 4 populations. These results showed that the genetic variation was mainly occurred among populations: $95 \%$ of the total variations. In other words, Ulex europaeus invaded and propagating in Maui, Hawaii, California and New Zealand did not show a large genetic difference within invaded populations. Genetic distance of the 37 samples of different mother tree (11, 4, 7, 15 from Maui, California, Hawaii and New Zealand respectively) was not significantly far; Ulex europaeus of the above four sites were inferred to be introduced from very close places. Though a very stable and accurate method to assess the genetic distance of the plants has not been innovated yet, microsatellites are inferred to be the most useful methods [5]. Whenever the invasiveness of a plant is discussed, the main driver is concluded as its variability. As not all the original places of the invasive species were recorded correctly, the records 
of the introduction of $U$. europaeus to the USA (Hawaii Island, Maui Island and California) and New Zealand were ambiguous. However, if the same plant species that have long genetic distance were compared, the variability could be ambiguous. Furthermore, could the results of the phenotypic plasticity of the samples of the same species from many spaciously different populations be discussed without any genetic assessments? The results of this investigation are used as the first benchmark before discussing about the phenotypic plasticity of $U$. europaeus sampled in the USA (Hawaii Island, Maui Island and California) and New Zealand; their genetic distance was not very far.

\section{Conclusions}

$U$. europaeus is known to originate in Western Europe and has been spread to the world. However, the introduction cases varied and some are not very well documented. Genetic variation of $U$. europaeus even in its originated place has been revealed by recent study [6], and it becomes mandatory to distinguish the genetic differences of Ulex europaeus in its invaded places far away from Western Europe for further studies such as strategies of invasibility. From the results shown in this study, the genetic distances of Ulex europaeus sampled in Maui, California, Hawaii and New Zeland are very close, and it could be the benchmark of the further studies.

Author Contributions: M.H. and E.N. designed investigation and experiments, analyzed data, and wrote the manuscript. All authors have read and agreed to the published version of the manuscript.

Acknowledgments: We would like to thank J.B. Friday with the University of Hawaii at Manoa, Pamela Scheffler with Hawaii Community College and staffs with Landcare Research and AgResearch of New Zealand for giving us advice, and staffs of US Fish and Wildlife Service in Hakalau and Land Manager, Jordan Jokiel of Haleakala Ranch for supporting sampling. This study was partly supported by a JSPS KAKENHI Grant (Grant No. 26257418).

Conflicts of Interest: The authors declare no conflicts of interest.

\section{References}

1. Gao, C.; Ren, X.; Mason, A.S.; Li, J.; Wang, W.; Xiao, M.; Fu, D. Revisiting an important component of plant genomes: Microsatellites. Funct. Plant Biol. 2013, 40, 645-661, doi:10.1071/FP12325.

2. Ainouche, A.; Bayer, R.; Cubas, P.; Misset, M.T. Phylogenetic relationships within tribe Genisteae (Papilionoideae) with special reference to genus Ulex. In Advances in Lugume Systematics Part 10, Higher Level Systematics; Klitgarrd, B.B., Bruneau, A., Eds.; Royal Botanic Gardens: Kew, UK, 2003; pp. 232-252.

3. Ainouche, A.; Mahe, F.; Affagard, M.; Ainouche, M.; Misset, M. Molecular evidence for an allopolyploid origin of the invasive European gorse, Ulex europaeus subsp. europaeus (Fabaceae, Genistae). In Proceedings of the International Conference on Polyploidity, Hybridization and Biodiversity, University of Rennes, Rennes, France, 17-20 May 2009; p. 202.

4. Blischak, P.D.; Kubatko, L.S.; Wolfe, A.D. SNP genotyping and parameter estimation in polyploids using low-coverage sequencing data. Bioinformatics 2017, 34, 407-415, doi:10.1093/bioinformatics/btx587.

5. Vieira, M.L.C.; Santini, L.; Diniz, A.L.; de Munhoz, C.F. Microsatellite markers: What they mean and why they are so useful. Genet. Mol. Biol. 2016, 39, 312-328, doi:10.1590/1678-4685-GMB-2016-0027.

6. Hornoy, B.; Atlan, A.; Roussel, V.; Buckley, Y.M.; Tarayre, M. Two colonisation stages generate two different patterns of genetic diversity within native and invasive ranges of Ulex europaeus. Heredity 2013, 111, 355-363.

7. Peakall, R.; Smouse, P.E. GenAlEx 6.5: Genetic analysis in Excel. Population genetic software for teaching and research-an update. Bioinformatics 2017, 28, 2537-2539.

8. R Core Team R: A Language and Environment for Statistical Computing; R Foundation for Statistical Computing: Vienna, Austria, 2018.

9. Yáñez-Cuna, J.O.; Arnold, C.D.; Stampfel, G.; Boryń, Ł.M.; Gerlach, D.; Rath, M.; Stark, A. Dissection of thousands of cell type-specific enhancers identifies dinucleotide repeat motifs as general enhancer features. Genome Res. 2014, 24, 1147-1156, doi:10.1101/gr.169243.113.

10. Hasegawa,Y.; Asano, R.; Kobayashi, Y.; Fukushima, J.; Takada, K. Comparison of NGS-SSR analyses and fragment analyses at SSR marker genotyping. J. Jpn. For. Sci. 2017, 128, 92, doi:10.11519/jfsc.128.0_92. 
11. Gouy, M.; Guindon, S.; Gascuel, O. SeaView version 4: A multiplatform graphical user interface for sequence alignment and phylogenetic tree building. Mol. Biol. Evol. 2010, 27, 221-224.

Publisher's Note: MDPI stays neutral with regard to jurisdictional claims in published maps and institutional affiliations.

(c) 2020 by the authors. Submitted for possible open access publication under the terms and conditions of the Creative Commons Attribution (CC BY) license (http://creativecommons.org/licenses/by/4.0/). 